\title{
Comparative Anatomical, Histological and Histochemical Study of the Liver in Three Species of Birds
}

\author{
Hani M. Hamodi Ali A. Abed \\ Ameer M. Taha* \\ Department of Biology \\ College of Education \\ University of Mosul \\ *E-mail: amhamdany@yahoo.com
}

(Received 16 / 1/2013 ; Accepted 18 / 3 / 2013)

\begin{abstract}
The aim of this study is to determine the anatomical features and histological structures as well as some histochemical aspects of the liver of three species of birds that differ in their nutrition, habitat and classification, by using light microscope. The birds were Larus canus, Agaporins fischeri and Numida meleagris. The results showed that the liver of the three species of birds was a dense, large and bilobed organ, it differed in size, color, lobes shape and presence of secondary lobes among the three species. The liver tissue of the three species consisted of hepatocytes which were radially arranged around the central veins interconnecting laminae of one to two cell thickness. The hepatocytes differed in size among the three species. Lumen of sinusoids contained mainly erythrocytes, macrophages and lining by the Kupffer cells. Histochemically, the hepatic cells in the three species of birds were weakly positive to periodic acid Schiff and alcian blue reactions, while they were negative to bromophenol blue reaction and they were moderately positive to Sudan black B reaction.
\end{abstract}

Keywords: Liver, Hepatocytes, Larus canus, Agaporins fischeri, Numida meleagris.

\section{درلسة تشربحية، نسجية وكيميائية نسجية طقارية للكبدفي نلالثة أنواع من الاليور}

\section{ll}

هذفت الدرلسة الحالية اللى التعرف على الصفلت التثريحية والتركيب النسجي فضلاً عن بعض النه الجوالب الكيميائية النجية للكبد في ثلاثة انواع من الطيور التي تختلف في تغذنيتها، بيئتها وتصنيفها

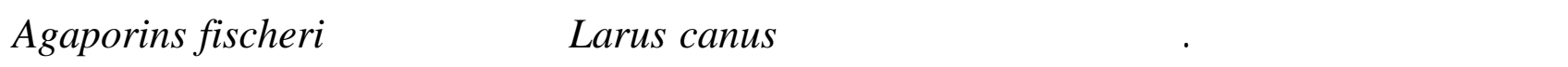
ونجاج غينيا Numida meleagris. أظهرت النتائج ان الكبد في الطيور الثلاثة عضو ثنائي الفص، كبير وكثيف وهو يختلف في الحجم، اللون،شكل الفصوص ووجود الفصوص الثانوية بين الطيور الثلاثة. شسبج الكبد في الطيور الثلاثة يتكون من الخلايا الكبية التي تترتبششعاعياً حول الوريد المركزي مكونة صفائح 
بسمك خلية اله خليتن. وتختلف الخلايا الكبية في الحهم بين الطيور الثلاثة. تجاويف الجيبانيت تحوي بصورة رئيسة على خلايا الدم الحمراء، الخلايا البلعمية الكبيرة وتبطن بخليايلايا كوفر. من النلحية الكينية الكيميائية

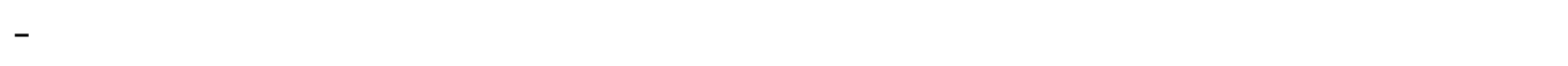

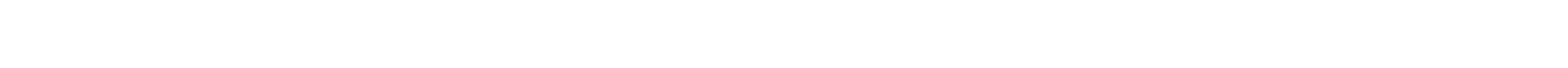
معتل مع السوسسودان ب.

\section{INTRODUCTION}

The liver is the largest internal organ of the body and the largest gland tissue. Its functions include assimilation of nutrients, production of bile, detoxification and maintenance of the body metabolic homeostasis which includes the processing of carbohydrates, proteins, lipids and vitamins. The liver also plays a key role in the synthesis of plasma proteins, like albumin, fibrinogen, and complement factors (Genten et al., 2009).

In avian species, the liver is a bilobed organ that lies in the mid-coelomic cavity of the body. The left and right lobes are joined at the midline. In most avian species, the left lobe is slightly smaller than the right lobe. Each lobe is drained by separate bile ducts into the distal ascending loop of duodenum. A gallbladder is an inconsistent finding, no gall bladder was identified in pigeons, many parrots (such as Amazons and Indian ringneck parakeets), and the ostrich. In those species with gallbladders (chickens, ducks, and geese), it was found on the visceral surface of the right lobe (Reavill, 2005; Coles et al., 2007).

The histology of the liver varies among species, but there were general features that are common in the majority of species (Genten et al., 2009). The structural and functional unit of the liver is the acinus, in which are both the hepatic lobule and portal triad. The hepatic lobule consists of hepatocytes that are the functional center of the liver, and in which the hepatocyte-sinusoidal structures are formed. The sinusoids are capillary networks, and are localized in the space between hepatic plates in which the hepatocytes are arranged. The portal triad is located in the portal spaces between the hepatic lobules, and contains branches of the portal vein, hepatic artery, and bile duct, lymph vessels and nerves. These vessels and ducts are surrounded by a connective tissue (Motta,1984; Akiyoshi and Inoue, 2004).

In vertebrates, the liver has a primary array based on hepatocytes, bile canaliculi and sinusoids, and structural differences occur among species in stroma and parenchyma threedimensional organization (Petcoff et al., 2006). Three patterns of organization of vertebrate hepatic parenchymal have been described by Eurell and Haensly (1982) and approved by other authors (Petcoff et al., 2006; Seyrafi et al., 2009; Monsefi et al., 2010; El-Bakary and El-Gammal, 2010). The first pattern of hepatic parenchyma arrangement consists of hepatocytes, which are radially arranged around a central vein in interconnecting laminae of two cells thickness, sinusoids separating each lamina. Bile canaliculi are located between adjacent hepatocytes. This pattern corresponds to the muralium or trabecular type, originally established by Elias and Bengelsdorf (1952) for birds and mammals. In the second pattern, sinusoids form an extensive network around the periphery of hepatocytes tubules whereas a bile canaliculus forms the center of the tubule. This pattern has been described in the 
“hagfish” Myxine glutinosa (Mugnaini and Harboe,1967). In the third pattern, hepatocytes are arranged in anatomized laminae around the central vein. The bile canaliculi are intracellular (Chapman, 1981).

The anatomical and histological structure of the liver has been investigated in a wide range of vertebrates species (Vicentini et al., 2005; Petcoff et al., 2006; Pérez and Lima, 2007; Bertolucci et al., 2008; Alshamarry et al., 2010; Firmiano et al., 2011; Sayrafi et al., 2011; Xie et al., 2011). Among the previously investigated birds, there were two different kinds of liver structure, the first kind is showing plates of two-cell thickness as in Gallus gallus, Anas acuta, Aix sponsa, Bonasa umbellus, Struthio camelus and Fulica americana whereas the second kind has uniformly one-cell-thick plates as in Sturnella magna, Sialia sialis, Spizella arborea and some other birds species (Elias and Bengelsdorf, 1952; Hickey and Elias,1954; Illanes et al., 2006; Stornelli et al., 2006).

Because of the existence of two different kinds of liver structure in one class of vertebrates, this study was conducted to investigate the anatomical and histological, as well as some histochemical aspects in the livers of three species of birds that differ in their nutrition, habitat and taxonomy, using light microscope. The birds were omnivorous Numida meleagris, grainivorous Agaporins fischeri and carnivorous Larus canus.

\section{MATERIAL AND METHODS}

The livers of ten Numida meleagris, six Agaporins fischeri and six Larus canus from both sexes have been included in this study. The birds were collected from different areas in Mosul city, Iraq.

The body cavity was opened through a midventral incision, the liver was immediately dissected out, fixed in neutral buffered formalin $(8 \%)$. liver pieces $(5 \mathrm{~cm})$ were then dehydrated in ascending grades ethanol (70\%, 80\%, 90\%, 95\% and 100\%), cleared in 2 changes of xylene, embedded in paraffin wax and sectioned at $(5 \mu \mathrm{m})$ (Drury and Wallington,1983). The sections were stained for general histological purposes with Delafieds Haematoxylin and Eosin (HE), Mallory's triple (TS), Toluidin blue (TB) and Azan (AZ) Stains (Bancroft and Stevens,1986). For carbohydrates histochemistry, sections were stained with Periodic Acid - Schiff technique (PAS) and Alcian Blue (AB) (pH 2.5), for proteins histochemistry, sections were stained with bromophenol blue (PB), and for lipids histochemistry, sections were stained with Sudan black B (SB) (Pears,1985). Histological examination was done by using light microscope (Reichert Neovar Type 300422) and photographed by using MDCE- 5A digital camera.

\section{RESULTS}

A gross examination of the liver of the three species of birds proved that it was a dense, large and bilobed organ that lied in the mid-coelomic cavity of the general cavity. The liver of the $N$. meleagris was larger than that the other two species and it was dark red in colour and consisted of left and right lobes which were joined cranially at the midline by an interlobar portion. The left lobe has concavity in its top where the heart stabilized, and it was split at the bottom into two secondary lobes, dorsal and ventral, the dorsal lobe was wider and shorter than the ventral lobe, while the right lobe has concavity from its ventral side where the gizzard was stabilized, and it didn't contain the incision that divided it into 
secondary lobes as it is in the left lobe. The gallbladder is well developed, has an elongated shape and attached to dorsal side of the right lobe and appears to be divided into secondary lobules at its bottom (Fig. 1a). The liver of the A. fischeri was light red in colour and consisted of left and right lobes like the liver of $N$. meleagris and has the same concavities in its lobes but it was smaller in size and there were no secondary lobes in the left lobe as well as it lacks the gallbladder (Fig. 1b). The liver of the L. canus appears to be dark red in colour and it is smaller in size than that of the $N$. meleagris but it is larger than that of $A$. fischeri and it consisted of two lobes as in the other two species. The left lobe was smaller in size from the right lobe and it has concavity in its top where is the gizzard was stabilized and it didn't have secondary lobules as in $N$. meleagris. The right lobe is greater and longer than the left lobe and didn't contain any concavity. The gallbladder was present as in $N$. meleagris, it is also well developed, has an elongated shape and looks like a grain of pumpkins, it is attached to the middle dorsal side of the right lobe (Fig. 1c).
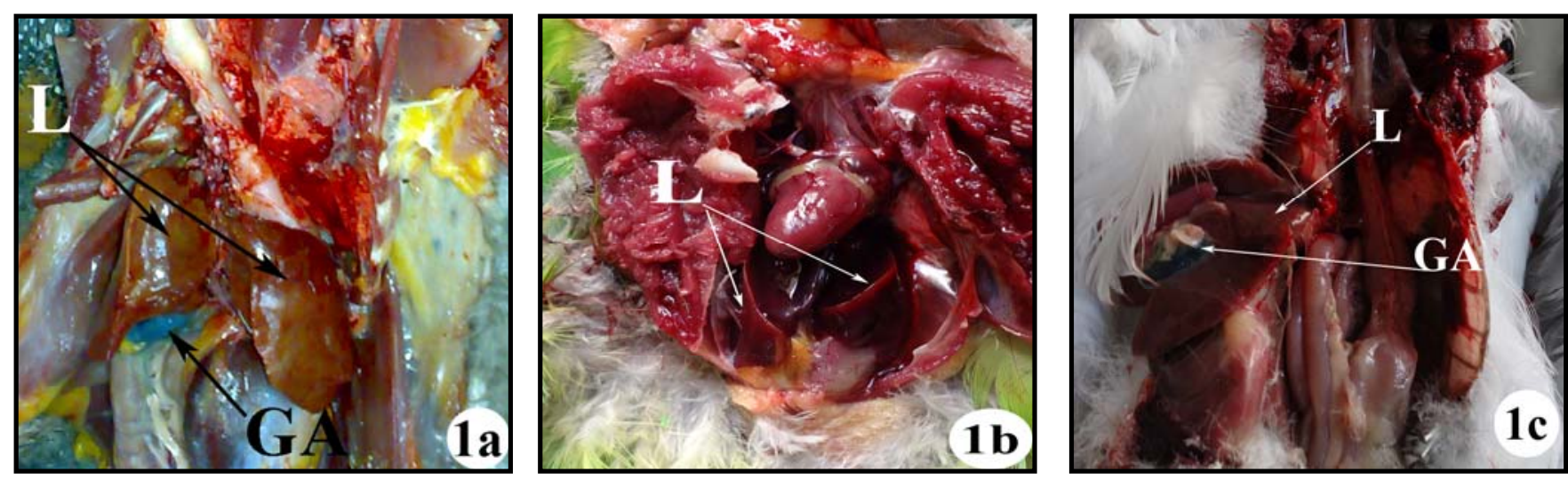

Fig. 1: Photograph of the liver of $N$. meleagris (a), A. fischeri (b) and L. canus (c). Showing the liver lobes $(\mathrm{L})$ and gallbladder (GA).

The histological examination of this study revealed that the liver in the three species of birds composed of a parenchyma covered by capsule which is composed of regular dense connective tissue that contains collagen and elastic fibers. This capsule appears to be thicker in the L. canus than the other two species. The capsule in the L. canus also contains lymphatic vessels, collagen fibers and fibroblasts which are not observed in the other two species. The bile ducts aren't noticed within the capsule of the liver of the three species (Fig. 2a, b, c).

The parenchyma of the liver in the three species of birds consists of hepatocytes which are arranged in plates, its thickness was either one cell or two cells around sinusoids. The hepatocytes constitute parallel cords to the capsule whereas it was arranged radially inward composing small lobules and acini. The hepatocytes were more compact in $N$. meleagris and $A$. fischeri, while it was more rarefied in L. canus, thus the blood sinusoids were larger in $L$. canus more than the other two species (Fig. 3a, b, c). The hepatocytes varied in shape among the three species, as well as, in the different portions of the liver in the same species. It appears to be polygonal, spherical, oval and irregular in N.meleagris, its thickness average was $(11.462 \pm 0.54 \mu \mathrm{m})$. Each hepatocyte contains a round, large and centrally situated nucleus, its diameter average $(3.415 \pm 0.17 \mu \mathrm{m})$ with a prominent dark nucleolus. The 
Plasma membrane which separated the hepatocytes was clear and thick in some areas and it was not clear thereby wasn't be identified in other areas (Fig. 4a, b). The hepatocytes in $A$. fischeri varied in shape from square, elongated to irregular, its thickness average (10.803 \pm $0.43 \mu \mathrm{m}$ ), each cell has a nucleus look like that present in the $N$. meleagris and its diameter average $(4.510 \pm 0.19 \mu \mathrm{m})$. The plasma membrane between the cells was less clear than in $N$. meleagris (Fig. 5a, b), whereas most of hepatocytes in L. canus appeared polygonal. Its thickness average $(13.902 \pm 0.64 \mu \mathrm{m})$, each cell has a nucleus similar to those in $N$. meleagris and $A$. fischeri hepatocytes, its diameter average $(4.998 \pm 0.210 \mu \mathrm{m})$. The nucleolus located centrally and the chromatin substance seem to be more dense, the plasma membrane was very difficult to be distinguished (Fig. 6a, b).
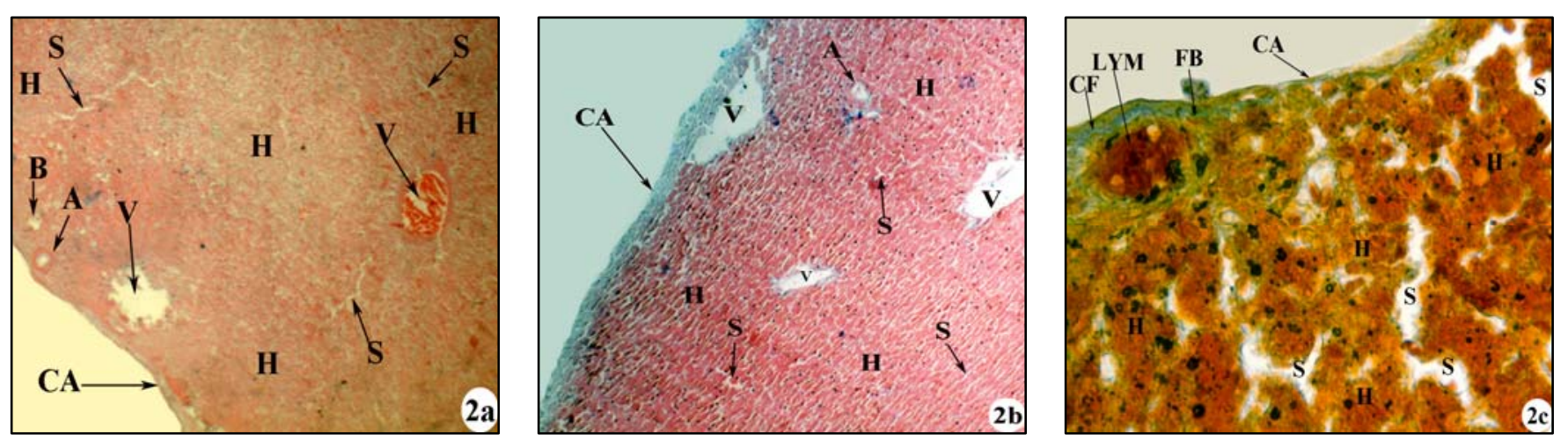

Fig. 2: Histological picture of the liver of $N$. meleagris (a) AB-4X, A. fischeri (b) AB-4X and L. canus (c) TS-40X. Show A, Artery ; B, bile duct; CA, Capsule; CF, collagen fibers; FB, fibroblast; $H$, hepatocyte; LYM, lymph vessel; S, sinusoid; V, Vein.
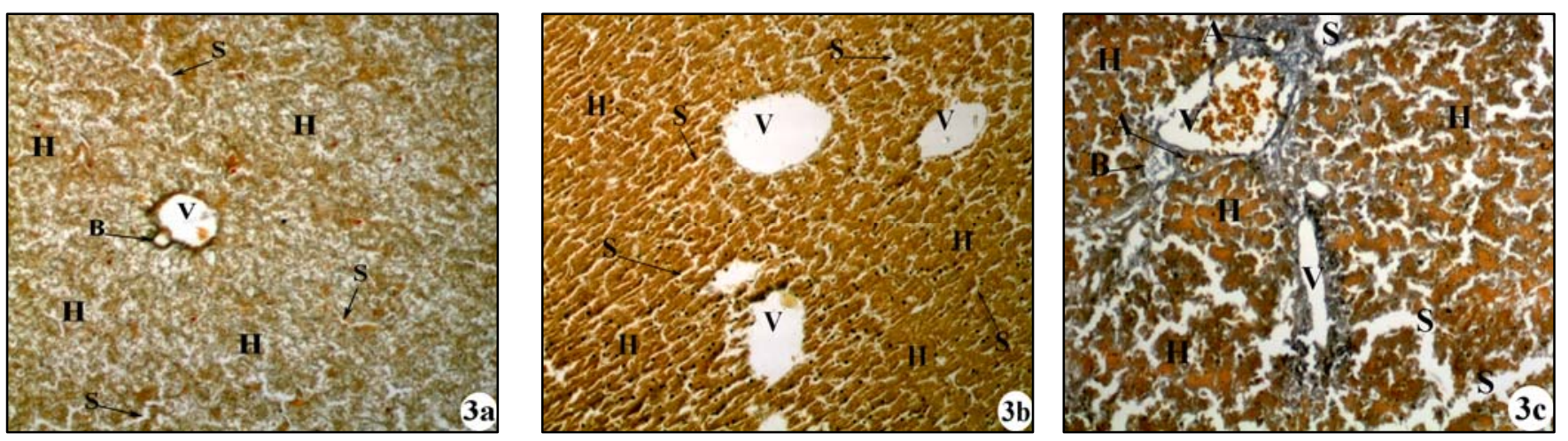

Fig. 3: Histological picture of the parenchyma of the liver of $N$. meleagris (a)TS-10X, A. fischeri (b) TS-10X and L. canus (c) TS-10X. Show A, Artery; B, bile duct; CA, Capsule; H, hepatocyte; S, sinusoid; V, Vein.

The sinusoids have an irregular shape and spread throughout the liver in the three species and appeared more wider in L. canus than in the other two species (Fig. 2a, 2b, 2c, 3a, 3b, 3c). Lumen of sinusoids contains mainly erythrocytes appeared throughout the spaces between the hepatic plates and cords and also contains macrophages. These cells appear more in number and spread wider in L. canus than the other two species. Large cells 
lining the luminal surface of the sinusoids with endothelial cells were present, these cells were known as Kupffer cells, which appeared larger in N. meleagris than in the other two species (Fig.4a, 4b, 5b, 6a, 6b).

Veins were scattered through the liver parenchyma of the three species of birds without a defined arrangement, these veins have mostly a circular shape and its average diameter in $N$. meleagris $(86.599 \pm 8.63 \mu \mathrm{m})$, in A. fischeri $(93.658 \pm 10.22 \mu \mathrm{m})$ and in L. canus $(128.101 \pm 12.27 \mu \mathrm{m})$, and they are surrounded by hepatic parenchyma. These veins

are lined by elongated cells, and seem to be more in number in A. fischeri than in the other two species. Sometimes the veins accompanied by either an artery or a bile duct in $N$. meleagris and L. canus (Fig. 2a, 2b, 3a, 3b, 3c, 6b). Triads consisted hepatic vein, artery and bile duct were detected at the periphery of parenchymal lobules, these areas are hepatic areas which appeared more distinct in $L$. canus. These areas contain in addition to the previously mentioned, collagen fibers in the three species and fibroblasts in $L$. canus only (Fig. 7a, b, c). The bile ducts were present in a small and medium-size its average diameters in $N$. meleagris and in $L$. canus $44.265 \pm 7.31 \mu \mathrm{m}$ and $31.180 \pm 7.09 \mu \mathrm{m}$ respectively, whereas it was absent in $A$. fischeri. Bile ducts are lined by simple cuboidal epithelium and surrounded by a loose connective tissue. There are elastic fibers or smooth muscle around larger ducts (Fig. 2a, 3a, 3c, 7a, 7c).
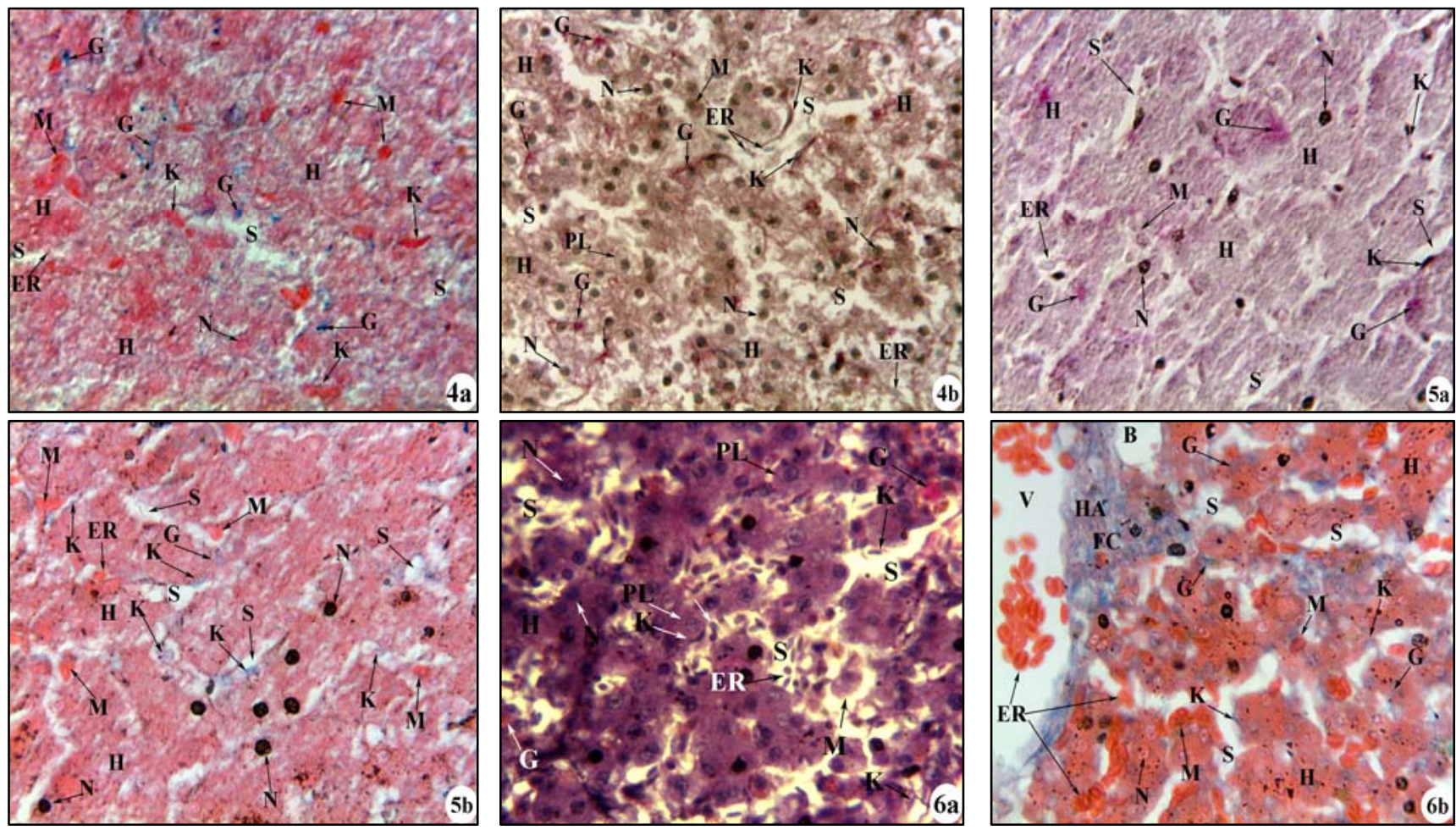

Fig. 4: Histological picture of the hepatocytes of $N$. meleagris (a)AB-40X, (b) PAS-40X. Fig. 5: Histological picture of the hepatocytes of A. fischeri (a) PAS-40X, (b) AB-40X. Fig. 6: Histological picture of the hepatocytes of $L$. canus (a) PAS-40X, (b) AB-40X. A, Artery; B, bile duct; CA, Capsule; CF, collagen fibers; ER, erythrocytes ; G, glycogen; $H$, hepatocyte;HA, hepatic area; $K$, Kupffer cells; $M$, macrophages ; N, nucleus; PL, plasma membrane; S, sinusoid; V, Vein. 
Histochemically, the stains showed that the main stored substances in hepatocytes are glycogen and lipids but the amount of these materials varied among the three species of birds. The hepatocytes were weakly reactive to PAS reaction in the three species of birds but the interaction was stronger in $N$. meleagris than the other two species. The glycogen appears as pink-colour deposits as identified throughout the cellular parenchyma of the liver especially in $N$. meleagris, while glycogen appears less frequent in $L$. canus and then in $A$. fischeri (Fig. 4b, 5a, 6a).These results were clarified by AB interaction, which showed glycogen as a light green patches in the hepatocytes and the glycogen was denser in $N$. meleagris than in the other two species (Fig. 4a, 5b, 6b). The hepatocytes in the three species of birds showed a negative reaction with PB stain for the proteins which indicated the lack of aggregations of protein inside the hepatocytes. The examination for lipids in the hepatocytes showed moderate to weak reaction to SB and more obvious in L. canus than in the other two species which is indicated by the presence of lipid inside hepatocytes. The lipids appeared as black oil droplets identified throughout the cellular parenchyma of the liver especially in L. canus, while lipids appeared less frequent in A. fischeri (Fig. 8a, 8b, 8c).
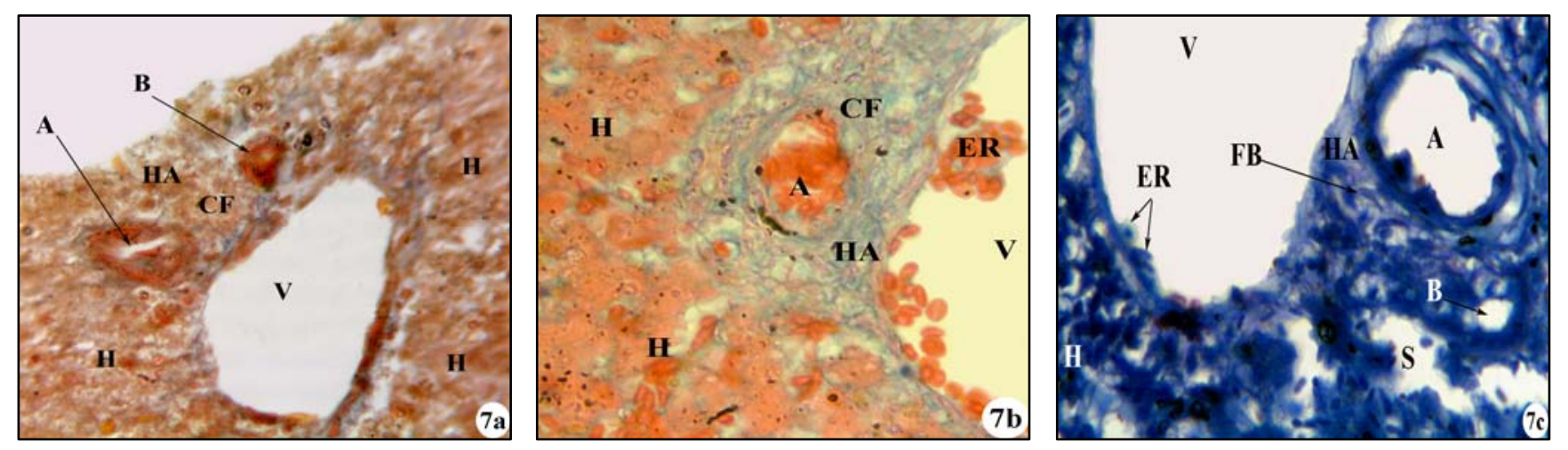

Fig. 7: Histological picture of the hepatic area of the liver of $N$. meleagris (a)TS-40X, A. fischeri (b) AB-40X and L. canus (c)TB-40X. Show A, Artery; B, bile duct; CF, collagen fibers; ER, erythrocytes; FB, fibroblast; H, hepatocyte; HA, hepatic area;S, sinusoid; V, Vein.
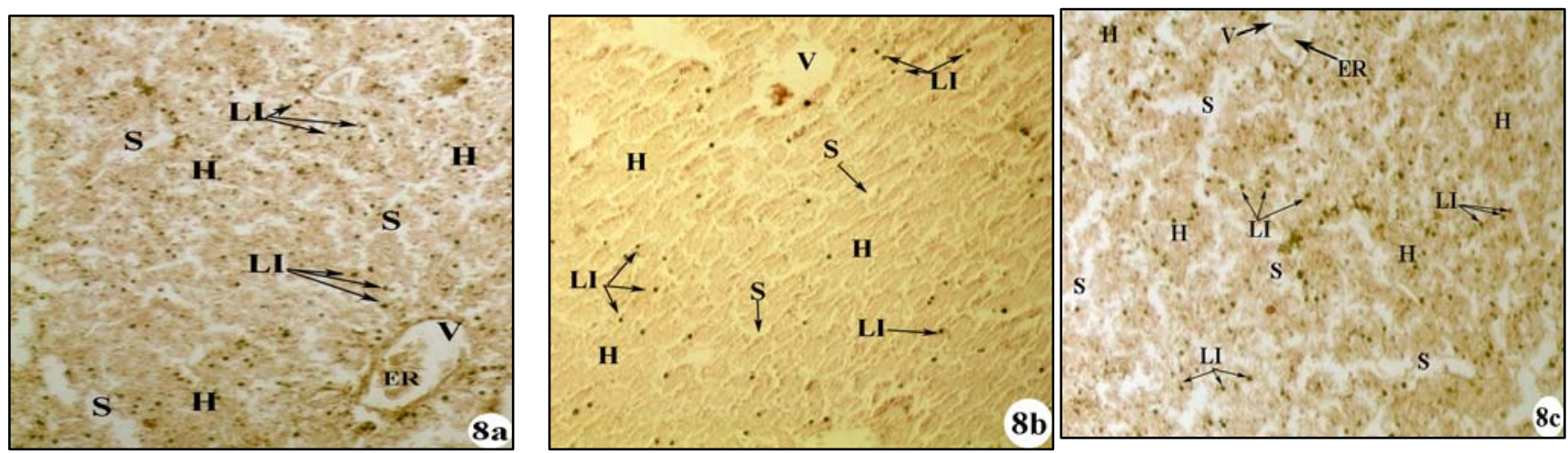

Fig. 8: Histological picture of the hepatocytes of the liver of $N$. meleagris (a)SB-40X, $A$. fischeri (b) SB-40X and L. canus (c) SB-40X. Show ER, erythrocytes; H, hepatocyte; HA, hepatic area; LI, lipids ; S, sinusoid; V, Vein. 


\section{DISCUSSION}

A gross examination of the present study showed that the liver of the three species of birds was a red bilobed and large organ that lied in the mid-coelomic cavity, these results are companied with the description of others birds (Whittow, 1998; Schmidt et al., 2003) such as captive bustards (Bailey et al., 1997), ostrich (Illanes et al., 2006; Stornelli et al., 2006) and other vertebrates (Petcoff et al., 2006; Seyrafi et al., 2009; Monsefi et al., 2010; El-Bakary and El-Gammal, 2010; Alshamarry et al., 2010). The size, weight and colour of the liver are dependent on the breed, age and nutritional status of the individual bird (Bailey et al., 1997). Also these results showed that the liver of the $N$. meleagris was larger than the other two species and this is probably relative to body size and omnivorous nutrition. The type of food consumed appears to have an important correlation with liver size, with insectivores and piscivores having the largest livers relative to body size (Bailey et al.,1997). One of the encouraging anatomical results that appeared in this study is the presence of two secondary lobes in the bottom of the left lobe of the liver of $N$. meleagris which wasn't noticed in the other two species. The later result also documented in the ostrich where the left lobe of the liver was subdivided into three secondary lobes while the right lobe was undivided (Stornelli et al., 2006). The gallbladder was noticed and appeared well developed in $N$. meleagris and L. canus whereas it was missed in A. fischeri. The gallbladder is usually present in many birds species with the exception of most parrots, pigeons and the ostrich. In the cockatiel (Nymphicus hollandicus), rheas, hoatzin and penguins, its presence is variable. In woodpeckers (Picidae), toucans (Ramphastidae) and barbets (Capitonidae) the gallbladder is exceptionally long in some individuals extending as far as the cloaca (Whittow, 1998; Stornelli et al., 2006; Coles et al., 2007).

The results of the current study also showed that the liver was surrounded by capsule composed of regular dense connective tissue, which appears thicker in the $L$. canus. This capsule also reported in other birds and vertebrates (Sheybani and Adibmoradi,2002; Schmidt et al., 2003; Illanes et al., 2006; Firmiano et al., 2011; Xie et al., 2011). While this capsule appeared consisting of loose connective tissue in some fishes (Alboghobeish and Khaksar-Mahabady, 2005; Sayrafi et al., 2011)

The liver in the three species of birds showed a hepatic parenchymal arrangement consisting of hepatocytes, which were arranged in either cords or plates of either one cell or two cells thickness around sinusoids. This histological structure of the liver didn't resemble that for many birds described by Hickey and Elias (1954), they founded that hepatocytes cords consisted of one cell thickness and little birds had either one or two cells. While it resembled the results of the studies that have described for many vertebrates that have hepatocytes cords consisted of one - two cell thickness (Stornelli et al., 2006; Bertolucci et al., 2008; El-Bakary and El-Gammal, 2010; Sayrafi et al., 2011; Xie et al., 2011). Akiyoshi and Inoue (2004) showed that the hepatocytes cords of the liver can be classified into three different types: (a) cord-like form (one-cell-thick plate type), (b) tubular form (two-cellthick plate type), and (c) solid form (several cell-thick plate type). The hepatocytes vary in shape among the three species, the reason of that may due to the genotype difference of each animal species (Alshamarry et al., 2010). The hepatocytes appeared larger in L. canus than in $N$. meleagris and A. fischeri sequentially, the large hepatocytes could be referred to the metabolic importance of these cells in the animal and they contributed more effectively in the metabolic processes. 
The sinusoids appear to be of irregular shape in the three species but it was wider in $L$. canus than the other two species. The hepatocyte-sinusoidal structure is physiologically important, not only because hepatocytes take up large molecules from the sinusoid, but also because of the abundant of macromolecules (e.g., lipoproteins, albumin, fibrinogen) are secreted into the sinusoid. In the cord-like form, hepatocytes are closely contacted with sinusoidal capillaries that form a dense network as in fishes and mammalian livers (Elias and Bengelsdorf, 1952; Motta, 1984; Akiyoshi and Inoue, 2004; El-Bakary and El-Gammal, 2010; Xie et al., 2011). Lumen of sinusoids contained erythrocytes and macrophages, the extrasinusoidal macrophages were first mentioned in the adult avian liver (Ohata et al.,1982; Kanai et al., 2007). Also the wall of sinusoids contained Kupffer cells that appears larger in $N$. meleagris than the other two species, Kupffer cells are important for the maintenance of liver functions under physiological and pathological circumstances (Wardle,1987). They play an important role in the modulation of immune responses via antigen presentation and suppression of cell activation and proliferation of T-cells (Sun et al., 2003). Kupffer cells specifically endocytose foreign particles and other noxious substances, including bacterial endotoxins, cause cell activation and the subsequent production of oxygen-derived free radicals, nitric oxide, eicosanoids, peptide leukotrienes, prostaglandins, as well as various cytokines, including TNF-alpha, IL1, IL6 and others (Decker,1998). Kupffer cells are also involved in the pathophysiologic response of liver injury (Arii and Imamura, 2000). Kupffer cells are major producers of cytokines in hepatic ischemia/reperfusion, play a stimulatory role in liver regeneration, which can reverse liver fibrosis (Takeishi et al.,1999; Mosher et al., 2001; Sakaida et al., 2003), and are critical for the progression of alcoholic injury (Enomoto et al., 2002). Kupffer cells and their products are also involved in modulating cell death by apoptosis of hepatocytes and other cell types (Deaciuc et al., 2002; Pagliara et al., 2003).

Our results showed that veins are scattered through the liver parenchyma of the three species of birds and appeared larger in diameter in L. canus. Sometimes the veins were accompanied either by an artery or a bile duct in $N$. meleagris and $L$. canus formed hepatic area, this arrangement also appeared in the other vertebrates (Petcoff et al., 2006; Seyrafi et al., 2009; Alshamarry et al., 2010; El-Bakary and El-Gammal, 2010; Monsefi et al., 2010). The bile ducts were present in a small and medium-size in $N$. meleagris and in L. canus whereas it were absent in A. fischeri. The biliary tree is a complex network of conduits that begins with the canals of Hering and progressively merges into a system of interlobular, septal, and major ducts which then coalesce to form the extrahepatic bile ducts, which finally deliver bile to the gallbladder and to the intestine. The biliary epithelium showing a morphological heterogeneity that is strictly associated with a variety of functions performed at the different levels of the biliary tree. The epithelial cells lining the bile ducts are actively involved in bile production by performing both absorbitive and secretory functions. More recently, other important biological properties restricted to cholangiocytes lining the smaller bile ducts have been outlined, with regard to their plasticity (i.e., the ability to undergo limited phenotypic changes), reactivity (i.e., the ability to participate in the inflammatory reaction to liver damage), and ability to behave as liver progenitor cells (Strazzabosco and Fabris, 2008).

Histochemically, current results showed that the hepatocytes were weakly reactive to $\mathrm{PAS}$ and $\mathrm{AB}$ reaction and negative reaction with $\mathrm{PB}$ and moderate reaction to $\mathrm{SB}$ in the 
three species of birds. These results confirm the importance of the liver in the metabolism of carbohydrates, fats and other nutrients and this also are comely with the results of previous studies on the liver in different vertebrates (Akiyoshi and Inoue, 2004; Petcoff et al., 2006; Seyrafi et al., 2009; El-Bakary and El-Gammal, 2010; Immanuel and Palavesam, 2010; Firmiano et al., 2011; Sayrafi et al., 2011; Xie et al., 2011).

Form these results, one could conclude that the liver structure in the three species of birds was resembled its structure in other birds and vertebrates. It is an important reservoir of glycogen and lipids in these birds, as well as it has an important protective effect by containing macrophages and Kupffer cells and this indicated the important role that the liver played in the immunological aspects in these birds especially in N. meleagris. The liver in the $L$. canus was more developed than the other two species followed by $N$. meleagris and perhaps the reason for that is due to the type nutrition of this bird.

\section{REFERENCES}

Akiyoshi, H.; Inoue, A. (2004). Comparative histological study of teleost livers in relation to phylogeny. Zool. Sci., 21(8), 841-850.

Alboghobeish, N.; Khaksar-Mahabady, M. (2005). Histological study of liver and pancreas in Cetonopharingodon idella. J. Sch. Vet. Med., 11, 25-34.

Alshamarry, H.A.; Sucar, D.K.; Taha, T.J. (2010). Comparative Histological study for The Iraqi Camels (Camelus dromedarius) liver and Cows (Bos indicus). J. Thi. Sci., 2(3),39-48.

Arii, S.; Imamura, M. (2000). Physiological role of sinusoidal endothelial cells and Kupffer cells and their implication in the pathogenesis of liver injury. J. Hepat. Panc. Sur.,7, 40-48.

Bailey, T.A.; Mensah-Brown, E.P.; Samour, J.H.; Naldo, J.; Lawrence, P.; Garner, A. (1997). Comparative morphology of the alimentary tract and its glandular derivatives of captive bustards. J. Anat., 191, 387-398.

Bancroft, J.D.; Stevens, A.(1986). "Theory and Practice of Histological Techniques". Churchill-Livingstone, London. pp. 41-59.

Bertolucci, B.; Vicentini, C.A.; Vicentini, I.B.F.; Bombonato, M.T.S. (2008). Light microscopy and ultrastructure of the liver of Astyanax altiparanae Garutti and Britski, 2000 (Teleostei, Characidae). Acta Sci. Biol. Sci., 30(1),73-76.

Chapman, G.B. (1981). Ultrastructure of the liver of the fingerling rainbow trout Salmo gairdneri, Richardson. J. Fish Biol.,18,553-567.

Coles, B.H.; Krautwald-Junghanns. M.; Orosz, S. E.; Tully, T. N. (2007). "Essentials of Avian Medicine and Surgery". Blackwell Science Ltd, a Blackwell Publishing Company. $14 \mathrm{p}$.

Deaciuc, I.; D'Souza, N.; Nikolova-Karakashian, M.; de Villiers, W.; Sarphie, T.; Hill, D.; McClain, C. (2002). The regulation of Fas (CD95/Apo-1)-mediated liver apoptosis in Kupffer cell-depleted mice. Hepato. Res., 24(2), 192.

Decker, K. (1998). The response of liver macrophages to inflammatory stimulation. Keio J. Med., 47, 1-9.

Drury, R.A.; Wallington, B.D. (1983). "Carleton's Histological Techniques". 5th ed., Oxford University Press, New York. 186 p. 
El-Bakary, N.E.R.; El-Gammal, H.L. (2010). Comparative histological, histochemical and ultrastructural study of the liver of Flathead Grey Mullet (Mugil cephalus) and Sea Bream (Sparus aurata). Glo. Vete., 4, 548-553.

Elias, H.; Bengelsdorf, H. (1952). The structure of the liver of vertebrates. Acta Anat., 14, 297-337.

Enomoto, N.; Takei, Y.; Hirose, M.; Ikejima, K.; Miwa, H.; Kitamura, T.; Sato, N. (2002). Thalidomide prevents alcoholic liver injury in rats through suppression of Kupffer cell sensitization and TNF-alpha production. Gastroenterology . 1, 291-300.

Eurell, J.A.; Haensly, W.E. ( 1982). The histology and ultrastructure of the liver of Atlantic croacker Micropogon undulatus L. J. Fish. Biol., 21,113-125.

Firmiano, E.M.S.; Cardoso, N.N.; Vieira, D.A.; Sales, A.; Santos, M.A.J.; Mendes, A.L.S Nascimento, A.A. (2011). Histological study of the liver of the lizard Tropidurus torquatus Wied 1820, (Squamata: Tropiduridae). J. Morphol. Sci., 28(3),165-170.

Genten, F.; Terwinghe, E.; Danguy, A.(2009)."Atlas of Fish Histology". Science Publishers, Enfi eld, NH, USA. 92 p.

Hickey, J.J. ; Elias, H. (1954). The structure of the liver of birds. Auk, 71, 458-462.

Illanes, J.; Fertilio, B.; Quijada, M.; Leyton, V.; Verdugo, F. (2006). Histologic Description of the Annexed Glands from the Ostrich Digestive System (Struthio camelus var. domesticus). Int. J. Morphol., 24(3), 297-302.

Immanuel, G.; Palavesam, A. (2010). Comparative study on the liver fatty acid profiles of the red toothed trigger fish (Odonus niger) from southwest coast of India. Ir. J. Fish. Sci., 9(1), 97-110.

Kanai, M.; Murata, Y.; Herbert, D.C.; Soji, T. (2007). Uptake Behavior of Embryonic Chick Liver Cells. Ana. Rec., 290, 862-874.

Monsefi, M.; Gholami, Z.; Esmaeili, H. (2010). Histological and Morphological Studies of digestive tube and liver of the Persian tooth-carp, Aphanius persicus (Actinopterygii: Cyprinodontidae). IUFS J. Biol., 69(1), 57-64.

Mosher, B.; Dean, R.; Harkema, J.; Remick, D.; Palma, J.; Crockett, E. (2001). Inhibition of Kupffer cells reduced CXC chemokine production and liver injury. J. Sur. Research., 2, 201-210.

Motta, P.M.(1984). The three-dimensional microanatomy of the liver. Arch. Histol. Jpn., 47, $1-30$.

Mugnaini, E.; Harboe, S.B. (1967). The liver of Myxine glut inosa: a true tubular gland. Z. Zell.,78, 341-369.

Ohata, M.; Tanuma, Y.; Ito, T. (1982). Electron microscopic study on avian livers with special remarks on the fine structure of sinusoidal cells. Okajimas Folia Anat Jpn., 58, 325-368.

Pagliara, P.; Carlà, E.C.; Caforio, S.; Chionna, A.; Massa, S.; Abbro L.; Dini, L.(2003). Kupffer cells promote lead nitrate-induced hepatocyte apoptosis via oxidative stress. Comp. Hepat., 2(1),8.

Pears, A.G.E. (1985). "Histochemistry Theoretical and Applied". 4th ed., Analytical Technology, Churchill Living Stone, Edinburgh, 898 p.

Pérez, W.; Lima, M. (2007). Anatomical description of the liver, hepatic ligaments and omenta in the coypu (Myocastor coypus). Int. J. Morphol., 25(1), 61-64. 
Petcoff, G.M.; Diaz, A.O.; Escalante, A.H.; Goldemberg, A.L. (2006). Histology of the liver Oligosarcus jenynsii (ostariophsi, characidae) from Los Pades Lake, Argentina. Ser. Zool., 96(2), 205-208.

Reavill, D. (2005). "A Review of the Avian Liver". Lecture given at the MASAAV 1997 Conference. 2005 Drury Reavill, Used with permission by MASAAV.

Sakaida, I.; Hironaka, K.; Terai, S.; Okita, K.(2003). Gadolinium chloride reverses dimethylnitrosamine (DMN)-induced rat liver fibrosis with increased matrix metalloproteinases (MMPs) of Kupffer cells. Life Sci., 8,943-959.

Sayrafi, R.; Najafi, G.; Rahmati-holasoo, H.; Aref, H.; Ramin, A.; Shokrpoor, S.; Ghadam, M. (2011). Histological study of hepatopancreas in Hi Fin Pangasius (Pangasius sanitwongsei). Afr. J. Biotech., 10(17), 3463-3466.

Sayrafi, R.; Najafi, Gh.; Rahmati-holasoo, H.; Hajimohammadi, B.; Athari, S.Sh. (2009). Histological study of Hepatopancreas in iridescent shark catfish (Pangasius hypophthalmus). J. Anim. Vet. Adv., 8(7),1305-1307.

Schmidt, R.E.; Reavill, D.R.; Phalen, D.N. (2003). "Pathology of Pet and Aviary Birds". A Blackwell Publishing Company. 67 p.

Sheybani, M.T; Adibmoradi, M. (2002). Histological study of the liver and pancreas and their ducts in Acipenser stellatus. J. Fac. Vet. Med. Uni. Tehran., 57(1), 19-23.

Stornelli, M.R.; Ricciardi, M.P.; Giannessi, E.; Coli, A. (2006). Morphological and histological study of the ostrich (Struthio camelus L.) liver and biliary system. It. J. Anat. Embryol., 111(1), 1-7.

Strazzabosco, M.; Fabris, L. (2008). Functional anatomy of normal bile ducts. Ana. Rec., 291, 653-660.

Sun, Z.; Wada, T.; Maemura, K.; Uchikura, K.; Hoshino, S.; Diehl, A.M.; Klein, A.S. (2003). Hepatic allograft-derived Kupffer cells regulate $\mathrm{T}$ cell response in rats. Liver Trans., 9(5), 489-497.

Takeishi, T.; Hirano, K.; Kobayashi, T.; Hasegawa, G.; Hatakeyama, K.; Naito, M. (1999). The role of Kupffer cells in liver regeneration. Arc. Histo. and Cyto., 5, 413-422.

Vicentini, C.A.; Franceschini-Vicentini, I.B.; Bombonato, M.T.S.; Bertolucci, B.; Lima, S. G.; Santos, A.S. (2005). Morphological Study of the Liver in the Teleost Oreochromis niloticus. Int. J. Morph., 23(3), 211-216.

Wardle, E.N. (1987). Kupffer cells and their function. Liver.7, 63-75.

Whittow, G.C. (1998). 'Sturkie’s Avian Physiology". 5th ed. Academic Press. 305 p.

Xie, Z.H.; Zhong, H.B.; Li, H.J.; Hou, Y.J. (2011).The structural organization of the liver in the Chinese fire-bellied newt (Cynops orientalis). Int. J. Morphol., 29(4),13171320. 